\title{
Thermal analysis of metal organic precursors for functional oxide preparation: thin films versus
} powders

P. Roura ${ }^{1 *}$, J. Farjas ${ }^{1}$, H. Eloussifi ${ }^{1,3}$, L. Carreras ${ }^{1}$, S. Ricart ${ }^{2}$, T. Puig ${ }^{2}$, X. Obradors ${ }^{2}$

1) GRMT, Dept. of Physics, University of Girona, Campus Montilivi, Edif. PII, E17071 Girona, Catalonia, Spain

2) Institut de Ciència de Materials de Barcelona, Consejo Superior de Investigaciones Científicas (ICMAB-CSIC), Campus de la UAB, 08193 Bellaterra, Catalonia, Spain

3) Laboratoire de Chimie Inorganique, Faculté des Sciences de Sfax, Université de Sfax, BP 1171, 3000 Sfax, Tunisia

* Corresponding author: pere.roura@udg.cat, FAX (34) 972418098

\begin{abstract}
The thermal decomposition of several metal organic precursors, used in the preparation of $\mathrm{YBa}_{2} \mathrm{Cu}_{3} \mathrm{O}_{7-\mathrm{x}}$ superconducting coated conductors ( $\mathrm{Cu}$ acetate, $\mathrm{Cu}, \mathrm{Y}$ and $\mathrm{Ba}$ trifluoroacetates and Ce propionate) is analyzed by means of several thermoanalytical techniques (TG/DTA, MS and DSC). In all cases, the metal organic precursors deposited as thin films decompose differently than powders from the same precursors. In thin films, decomposition is facilitated by the easier transport of reactive gas from the surrounding atmosphere and by the easier out-diffusion of volatile products. Consequently, films decompose at lower temperature and are more sensitive to the presence of any residual reactive gas in the furnace. Good thermal contact with the substrate is also shown to minimize overheating in films and avoid combustion processes that are otherwise often observed during the thermal decomposition of powders. Finally, the formation and stability of intermediate products towards the oxide formation, such as metal fluorides, differs in films because of the easier gas exchange. With respect to powders, these compounds are much less stable in films, where their decomposition temperature can be lowered by several hundreds of degrees Celsius. While in some cases the behaviour of films can be predicted by analyzing varying masses of precursor powders, this is not always the case. Therefore, thermal analysis carried out on films is recommended to avoid erroneous conclusions about materials preparation drawn from powders.
\end{abstract}

Keywords: pyrolysis, thermal decomposition, YBCO 


\section{I.- Introduction}

Thermal decomposition of metal organic precursors is a current route for the synthesis of metal oxides in the form of powders, thin films or nanostructures [1,2,3,4,5]. Films can be obtained by Chemical Solution Deposition (CSD) techniques. A solution containing the precursor is spread over a substrate and, after solvent evaporation, the film is pyrolyzed. By controlling the precursor concentration and spreading conditions, film thickness can vary from tens of $\mathrm{nm}$ to several microns. These techniques allow fabrication of low-cost oxide single or multilayers that find application in microelectronics [6], high-temperature superconductors [7, 8, 9], photovoltaic energy conversion [10], optical layers [11], ferroelectric devices [12], etc.

The oxide quality critically depends on the pyrolysis conditions (heating rate to the isothermal stage, temperature and furnace atmosphere) when metal organic decomposition takes place. At this point, thermoanalytical techniques (notably thermogravimetry (TG) coupled with mass spectrometry (MS) or infrared spectroscopy) are very useful because they give information about the decomposition temperature, decomposition mechanism and kinetics and allow prediction of the evolution of the reaction when the material is submitted to a particular temperature program [13]. Since the signal delivered by any technique is proportional to the sample mass, $\mathrm{m}_{\mathrm{i}}$, thermal analysis experiments are usually done with the precursor in the form of powders (typically, $\mathrm{m}_{\mathrm{i}}>5 \mathrm{mg}$ ) [6], whereas experiments on films are very scarce (typically, $\mathrm{m}_{\mathrm{i}}<1 \mathrm{mg} / \mathrm{cm}^{2}$ ). This is so because, for the low masses of films, the TG baseline instability impedes the accurate analysis of the decomposition mass-loss curve. Consequently, the question arises: "Is the information delivered by powders (e.g. decomposition temperature, final or intermediate products and their dependence on the atmosphere) valid for films?"

In this paper, we will show that, in general, one should expect a negative answer whenever the decomposition kinetics is controlled by a transport step. To be more specific, films are expected to decompose differently than powders when the decomposition is controlled by: a) transport of reactive gas (usually $\mathrm{O}_{2}$ or $\mathrm{H}_{2} \mathrm{O}$ ); b) evolution of gaseous species (reaction products or solvents) or c) heat transport out of the sample (see the summary given in Fig.1). All these aspects are not exclusive of decomposition processes but are intrinsic to most solid-gas reactions [14]. The fact is that, for most precursors we have analyzed to date, significant differences have been observed between powders and films. So, it is clear that optimization of the pyrolysis step can be hardly achieved with thermal analyses on powders. It is necessary to develop experimental procedures for measuring the decomposition 
directly on films or, alternatively, to establish criteria that would help to deduce the behaviour of films from that of powders.

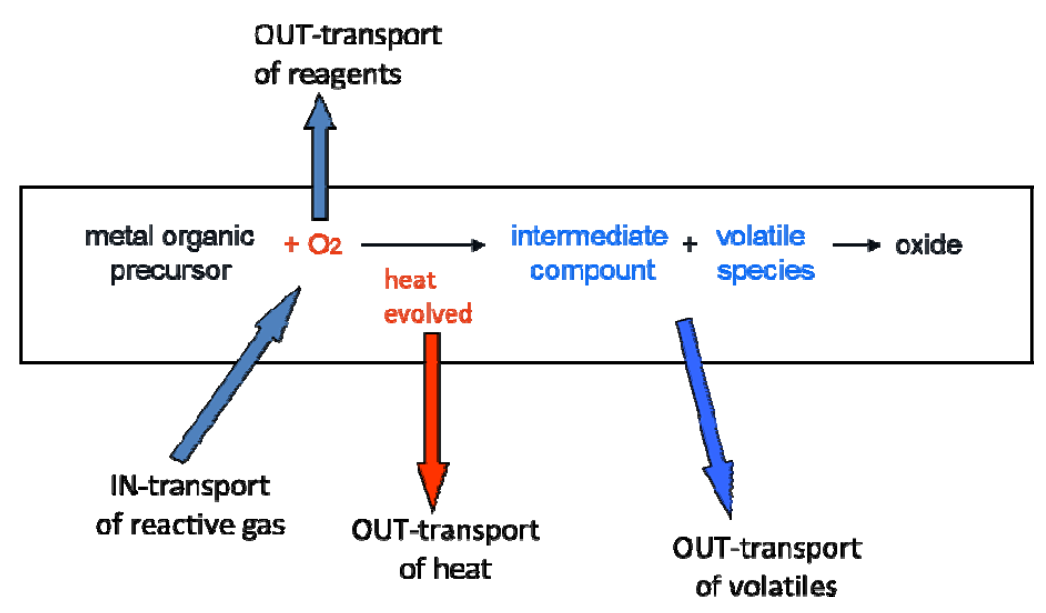

Figure 1.- Scheme showing several transport processes that can have some influence on the formation and microstructural development of oxide powders and films.

Substrates can also have a catalytic effect on decomposition reactions through their chemical terminations (e.g. $\mathrm{H}^{+}$terminations on the surface of glass substrates enhance the decomposition of $\left.\mathrm{Y}(\mathrm{TFA})_{3}[15]\right)$ or by promoting epitaxial growth of the oxide. Film deposition requires the preparation of a solution that may in turn modify the molecular structure of the precursor. However, such an effect is absent in this present study because of the chemical similarity between solvents and salts (e.g. acetic acid and acetates). Furthermore, a surface energy difference between films and powders may also exist. Nevertheless, as these effects are not related to any transport mechanism they will not be analysed here.

The examples given below correspond to metal organic precursors used for the fabrication of $\mathrm{YBa}_{2} \mathrm{Cu}_{3} \mathrm{O}_{7-\mathrm{x}}(\mathrm{YBCO})$ superconducting tapes. These tapes consist in the active superconductor layer (1$2 \mu \mathrm{m}$ thick) separated from the metallic substrate by one or several oxide thin buffer layers such as ceria $\left(\mathrm{CeO}_{2}\right)$ or other oxides [16, 17]. Additional examples published in a shorter format can be found in ref. [18].

\section{II.- Experimental}

Most precursors were used in their commercial form of powders: anhydrous $\mathrm{Y}(\mathrm{TFA})_{3}$ and $\mathrm{CuAc}_{2}$, and $\mathrm{Cu}(\mathrm{TFA})_{2}$ hydrated were supplied by Aldrich. Ce propionate was synthesised from $\mathrm{Ce}$ acetate (see details in [19]) and $\mathrm{Ba}(\mathrm{TFA})_{2}$ from Ba carbonate [20]. The powders were analysed inside alumina pans without cover to facilitate gases exchange (crucible section area, $0.2 \mathrm{~cm}^{2}$ ). To obtain thin films, the 
precursor salts were dissolved in acetic or propionic acid and, then, a microdrop was spread on an appropriate substrate and dried below $100^{\circ} \mathrm{C}$ or, alternatively, a spin coater was used. Thin glass discs, platinum foils or silicon and $(001) \mathrm{LaAlO}_{3}$ single crystalline substrates were used depending on the experiment (typical area of one substrate side was $1 \mathrm{~cm}^{2}$ ). To increase the mass of the samples, films were deposited on both substrate sides and several (usually two) substrates were kept some mm apart inside the TG furnace, to allow gas exchange with the furnace atmosphere. The quoted thickness of the films is their "nominal thickness", i.e. the thickness the film would have if transformed into a dense oxide. In our studies we have found two kinds of films: a) aggregates of particles [15] and b) dense films [21]. However, the different behaviour between powders and films does not depend on this structural feature but on the fact that gas and heat transport is easier in films (see next section).

TG analyses were done with a TGA851 ${ }^{\mathrm{e}} \mathrm{LF}$ apparatus from Mettler Toledo and a Setsys Evolution apparatus from Setaram under continuous flow of high-purity gases (usually $40 \mathrm{~mL} / \mathrm{min}$ ). The TG curves were corrected by the apparatus baseline, measured during a consecutive measurement under the same conditions. Additionally, the final mass of the sample was always measured and compared with that deduced from the TG curve. Significant discrepancies led us to discard experiments. These precautions were essential for the experiments on films. These apparatus simultaneously delivered the differential thermal analysis signal (DTA). For the differential scanning calorimetry (DSC) measurements, the DSC822 from Mettler Toledo was used. And, finally, mass spectroscopy (MS) measurements were taken simultaneously to the TG curves with an MKS Spectra Quadrupole (Micro Vision Plus), which detects molecular fragments with $\mathrm{m} / \mathrm{z}<300 \mathrm{amu}$.

Several apparatus were used for the X-ray diffraction experiments (XRD): a) Smart Apex diffractometer of Bruker AXS (with Mo x-ray source) where collection of the diffracted photons was done with a CCD detector that increases the experimental sensitivity at the expense of resolution; b) conventional D8 Advance diffractometer from Bruker AXS in the $\theta-2 \theta$ configuration (Cu x-ray source); and c) thin film diffractometer PANalytical model X'pert PRO MRD (Cu X-ray source). XRD spectra were analyzed using eva software from SOCABIM and the JCPDS database from the International Centre of Diffraction Data.

\section{III.- Results and discussion}

III.1.- Transport of reactive gas: decomposition of Ce propionate 
The dependence on $\mathrm{m}_{i}$ is easily understood due to the reactive gas consumption at the sample surface. Higher $\mathrm{m}_{i}$ implies faster gas consumption and, consequently, a less reactive atmosphere near the sample because of the higher concentration gradient between the sample surface (at the bottom of the crucible) and the free atmosphere (at the top of the crucible). Thus, $\mathrm{T}_{\mathrm{dec}}$ must move towards the value for inert conditions when $\mathrm{m}_{i}$ increases. In the case of films, a higher mass corresponds to a thicker film. Consequently, the reactive gas must diffuse over a greater distance through the solid precursor and as a result decomposition will be slower (higher $\mathrm{T}_{\mathrm{dec}}$ ) for thicker films. Finally and given the same precursor mass for powders and films, because the crucible section is usually much smaller than the substrate area, the reactive gas will reach the film surface more easily than the powder and thus $T_{\text {dec }}$ will be minimal for thin films.

These predictions are aptly illustrated by the TG curves corresponding to the decomposition of Ce propionate in air and $\mathrm{N}_{2}$ (Figs. 2 and 3) $[11,19]$. Notice that powders decompose in air at a lower temperature when $\mathrm{m}_{i}$ diminishes, and that decomposition begins at the same temperature as in the inert atmosphere when $m_{i}$ is high enough (see asymptotic behaviour in Fig. 3). Similarly and as to be expected, films decompose in air at a lower temperature when they become thinner (Fig. 2). The most interesting fact for our discussion is that, for the same initial mass $\mathrm{T}_{\mathrm{dec}}$ is lower for thin films than for powders (Fig. 3). This behaviour is mainly due to the lower mass per unit area (substrate area for films and crucible section for powders $)$ of films. The thinnest film we measured $(0.17 \mu \mathrm{m})$ decomposed at around $120^{\circ} \mathrm{C}$ below the decomposition temperature of $10 \mathrm{mg}$ of powders. This difference provides us with an insight into the enormous errors that could be made if one applied the information obtained from powders to thin films.

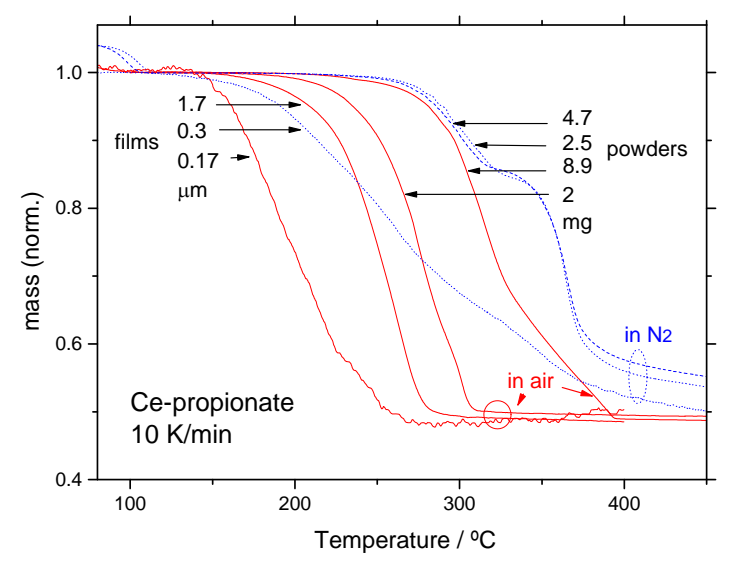

Figure 2.- TG decomposition curves of $\mathrm{Ce}$ propionate films and powders in air (solid lines) and in $\mathrm{N}_{2}$ (dashed lines). Quoted film thicknesses refer to the expected thickness of dense $\mathrm{CeO}_{2}$ films. 

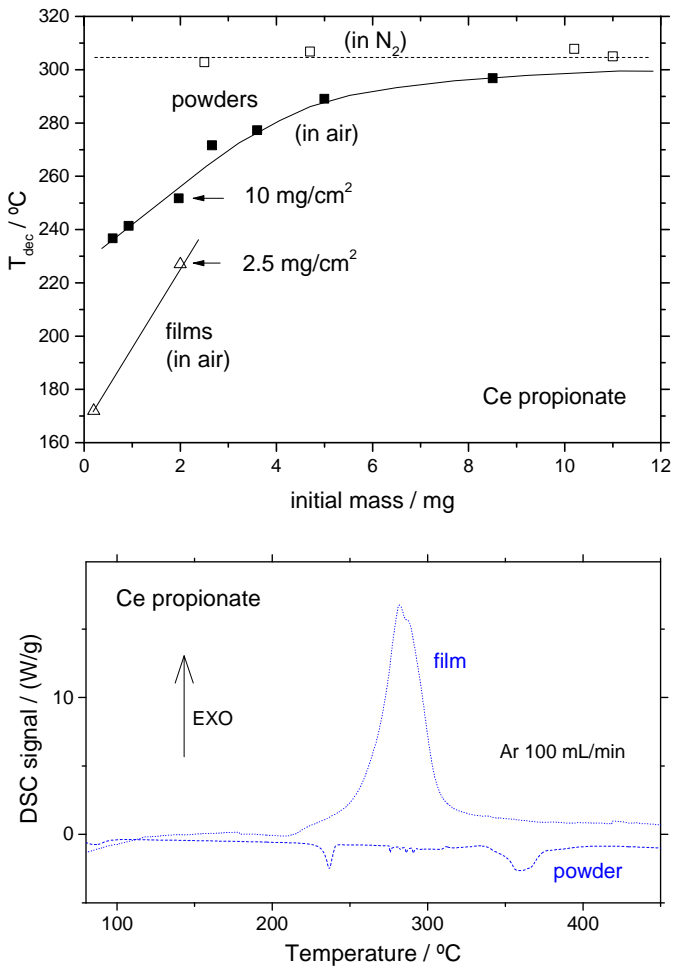

Figure 3.- Decomposition temperature (defined as the temperature where $\mathrm{m} / \mathrm{m}_{\mathrm{i}}=0.9$ ) extracted from the TG curves of Fig. 2 (for clarity, only selected curves were shown).

Figure 4.- DSC curves measured in a nominally inert atmosphere.

For experiments carried out in an inert atmosphere, $T_{\text {dec }}$ should be independent of $m_{i}$ and share the same value for films and powders. In Fig. 2 the curves of the powders coincide above $2.5 \mathrm{mg}$. However, and surprisingly, a thin film begins to decompose at a much lower temperature. We consider that, in this case, the partial pressure of the residual oxygen in the furnace was high enough to enhance the decomposition rate of the film, whereas it was not able to modify the inert conditions near the powders. This explanation is consistent with the complementary DSC experiments carried out on the powders and the one film tested. Fig. 4 depicts that when treated under the same conditions $(100 \mathrm{~mL} / \mathrm{min}$ of Ar $)$, the film reacts with the oxygen giving rise to a highly exothermic peak, whereas the decomposition of powders is endothermic as if the atmosphere were completely inert. In other words, we can conclude that thin films are much more sensitive to traces of oxygen or any reactive gas during pyrolysis than powders are.

Before closing this section, we ought to remark that the different behaviour reported in this and the subsequent section, applies to films that are "thin enough". The trend observed in $\mathrm{T}_{\mathrm{dec}}$ as the film mass (thickness) increases (Fig. 3) indicates that Ce propionate films with $\mathrm{m}_{i}>4 \mathrm{mg}(>3.5 \mu \mathrm{m}$ ) would decompose at a higher temperature than would be required for the same amount of powders. This is because oxygen has to diffuse through the film to reach the unreacted precursor and while it may not be completely dense, it will always be denser than the aggregates of particles in the powders. Consequently 
for thick films, the lower diffusivity through the film will balance the easier gas transport from the furnace atmosphere to the film surface.

\section{III.2.- Evolution of gaseous species: decomposition of $\mathrm{Ba}(\mathrm{TFA})_{2}$}

Local atmosphere composition near the sample can also be affected by the volatiles that result from decomposition and, due to the reverse reaction, a higher concentration of products may reduce the overall reaction rate. This effect is very common in carbonates, whose decomposition temperature is lowered by hundreds of degrees when the sample mass is reduced, due to the lower local concentration

of $\mathrm{CO}_{2}$. It has also been reported in the studies devoted to determine the decomposition temperature of YBCO at very low oxygen partial pressures [22]. The reduction of $\mathrm{T}_{\operatorname{dec}}$ in $\mathrm{Ba}(\mathrm{TFA})_{2}$ films with respect to powders (Fig. 5) can be explained in a similar way.

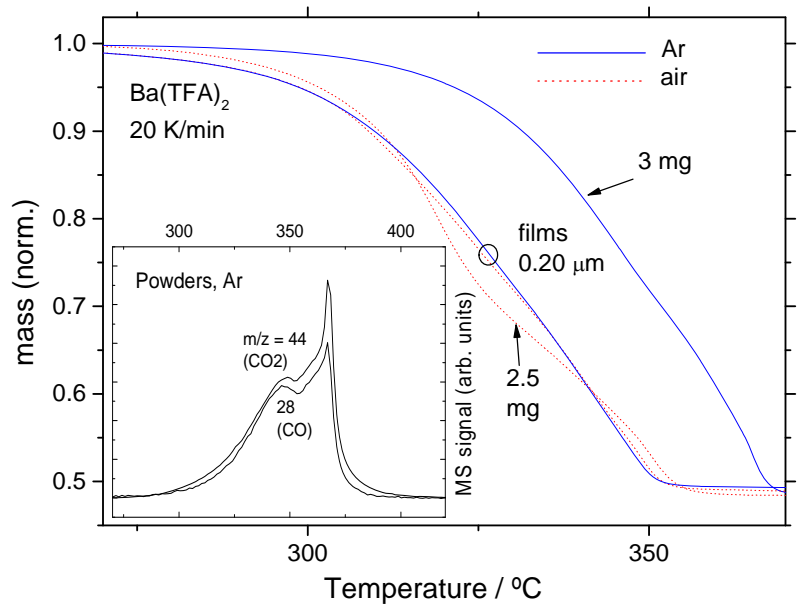

Figure 5.- TG curves of $\mathrm{Ba}(\mathrm{TFA})_{2}$ powders and films decomposition in $\mathrm{Ar}$ and air. Inset: MS curves of $\mathrm{CO}$ and $\mathrm{CO}_{2}$ measured during powder decomposition in Ar.

First of all, notice that $\mathrm{Ba}(\mathrm{TFA})_{2}$ powders decompose at a lower temperature in air than in Ar (Fig. 5). Although this fact may induce to think that decomposition is triggered by reaction with oxygen, this is not the case. DSC measurements show that the decomposition enthalpy is more exothermic in air by just the heat evolved during the oxidation of one mol of $\mathrm{CO}$ to $\mathrm{CO}_{2}$ [20]. In other words, oxygen molecules do not participate in the primary decomposition reaction but in a secondary reaction with $\mathrm{CO}$ out of the sample. This fact, together with MS results, notably the equal amounts of $\mathrm{CO}$ and $\mathrm{CO}_{2}$ detected in inert atmosphere (inset of Fig. 5), led us to propose the following overall decomposition reaction:

$$
\mathrm{Ba}(\mathrm{TFA})_{2}----->\mathrm{BaF}_{2}+\mathrm{CF}_{3} \mathrm{CFO}+\mathrm{CO}_{2}+\mathrm{CO} \text {. }
$$

So, in air oxygen reacts with $\mathrm{CO}$ and reduces its concentration near the sample, thus reducing the inverse reaction rate and enhancing the decomposition rate in powders (i.e., lowering $\mathrm{T}_{\mathrm{dec}}$ ). 
On the contrary, experiments carried out in films show that their $\mathrm{T}_{\mathrm{dec}}$ is identical in air and Ar [21] and lower than for powders in Ar (Fig. 5). This result is consistent with reaction (1) if gas exchange is so easy in films that $\mathrm{CO}$ concentration is so low that the reverse reaction can be neglected even in the absence of oxygen.

This example tells us that, even if $\mathrm{T}_{\mathrm{dec}}$ clearly depends on the presence of reactive gas species (usually $\mathrm{O}_{2}$ ) in powders, this dependence may be lost when dealing with films.

\section{III.3.- Heat transport: combustion of Cu(II) acetate}

When decomposition of metal organic compounds takes place in air or in pure oxygen, the process is highly exothermic. Consequently, the sample temperature will be higher than that measured by the TG apparatus and indicated on the x-axis of a mass-loss curve. This sample overheating will depend on the heat dissipation paths [23]. For large samples in powder form, the process will be more adiabatic and, eventually, combustion can occur. Combustion begins with a local overheating that leads to local thermal runaway (ignition) that propagates all along the sample as a combustion front. This phenomenon can be identified in a TG curve by an abrupt mass loss (solid curve in Fig. 6) that often begins with a slope discontinuity. Decomposition reaches completion in few seconds indicating that the local temperature at the combustion front is hundreds of Celsius above the measured temperature [24].

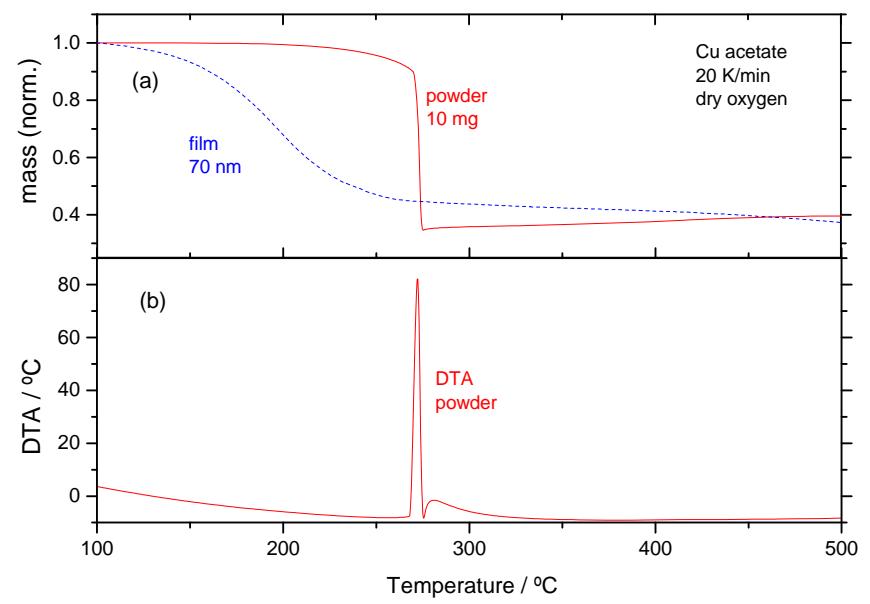

Figure 6.- a) TG decomposition curves of $\mathrm{Cu}$ acetate in dry oxygen for powders and one film; b) the corresponding DTA curve for the powder showing that its decomposition entails high overheating of the sample leading to combustion (the DTA signal from the film was below the apparatus sensitivity). 
Combustion synthesis has been recently proposed as a general route for the low-temperature fabrication of oxide thin films [6]. However, calculations shown that the very high thermal conductance between the substrate and the film makes it very difficult to reach the overheating needed for combustion and, consequently, we think that combustion of thin films (say, below $1 \mu m$ ) is very unlikely [25]. In fact, we have observed combustion in several precursor powders but this phenomenon was always absent for the corresponding films. The case of $\mathrm{Cu}$ acetate in dry oxygen constitutes a nice example (Fig. 6).

Due to the oxygen depletion effect discussed above, decomposition of $\mathrm{Cu}$ acetate powders begins at a temperature higher than that of films. For the experiment reported in Fig. 6, decomposition of powders becomes unstable at $270^{\circ} \mathrm{C}$ where the abrupt mass loss indicates that combustion occurs. This mass-loss event is accompanied by a sharp differential thermal analysis (DTA) peak indicating a sudden heat evolution (Fig. 6b). Although, the DTA gauge recorded a sample overheating of $80^{\circ} \mathrm{C}$, the local temperature at the combustion front is much higher. The interesting point here is that, in contrast with powders, the film TG curve is smooth (dotted curve in Fig. 4a), i.e. no combustion takes place. Comparison of both curves in Fig.6a tells us that TG experiments on powders that experience combustion to analyse the thermal evolution of films is nonsense and, probably, a common error [6, 26].

The first three examples discussed so far (Ce propionate, $\mathrm{Ba}(\mathrm{TFA})_{2}$ and $\mathrm{Cu}$ acetate) lead us to point out that, in general, films decompose at a temperature lower than powders. Therefore, researchers interested in low-temperature processing of CSD films should take it into account. We have recently shown that ceria films can be obtained at a temperature as low as $160^{\circ} \mathrm{C}$ from $\mathrm{Ce}$ propionate [11]. Similarly, $\mathrm{CuO}$ nanocrystalline films can be obtained at $180^{\circ} \mathrm{C}$ through isothermal decomposition of $\mathrm{Cu}$ acetate. The XRD curves of powders and a thin film treated at $180{ }^{\circ} \mathrm{C}$ for $1 \mathrm{~h}$ are shown in Fig. 7. Whereas $\mathrm{Cu}$ acetate remains the dominant phase (perhaps the only phase) in the powders, the film has been decomposed into $\mathrm{CuO}$.

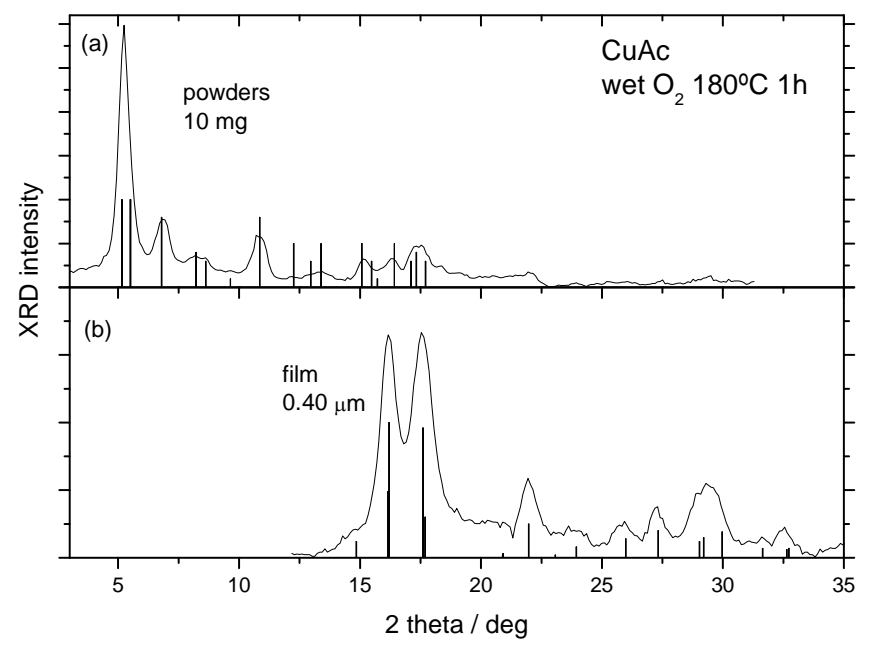

Figure 7.- $\mathrm{XRD}$ of the product of $\mathrm{Cu}$ acetate after heat treatment at $180^{\circ} \mathrm{C}$ lasting $1 \mathrm{~h}$ in wet $\mathrm{O}_{2}$. The curve of powders (a) has the characteristic peaks of $\mathrm{Cu}$ acetate (i.e. no decomposition has occurred), whereas, the curve of one film (b) corresponds to $\mathrm{CuO}$. 
The two last examples that follow deal with the differences between films and powders with respect to the formation and stability of intermediate decomposition products.

\section{III.4.- Gas exchange and combustion: reduction of $\mathrm{Cu}$}

In some cases, decomposition of metal organic precursors entails a change in the metal oxidation state. Decomposition of $\mathrm{Au}$ [27], $\mathrm{Ni}$ [28] and Ag acetates [29] in an inert atmosphere leads to the formation of metallic nanoparticles, whereas oxidation of $\mathrm{Ce}(\mathrm{III})$ into $\mathrm{Ce}(\mathrm{IV})$ is usually observed for ceria precursors even in an inert atmosphere [19]. The effect of oxidizing or reducing species produced during decomposition or coming from the furnace atmosphere will depend, in general, on their transport across the sample. Since this transport is easier in films than in powders, differences of the oxidation state may be expected between films and powders. This point will be analyzed for the particular case of $\mathrm{Cu}$ acetate decomposition in dry oxygen.

Let us analyze first the TG curves measured on varying amounts of powder that are plotted together in Fig. 8. To deduce the nature of the decomposition products, the masses of $\mathrm{CuO}, \mathrm{Cu}_{2} \mathrm{O}$ and metallic $\mathrm{Cu}$ are indicated as horizontal lines. Note that at $600^{\circ} \mathrm{C}$ where the mass becomes stable (no further increment is observed above this temperature), all the curves lay below the mass of $\mathrm{CuO}$ (the only thermodynamically stable state in dry oxygen at this temperature). This means that some $\mathrm{Cu}$ has been lost during decomposition due to precursor evaporation. This effect is well known in YBCO thin film growth processes by CSD, where an initial excess of $\mathrm{Cu}$ precursor to compensate for it is used or decomposition is done in a wet atmosphere to avoid the evaporation of the $\mathrm{Cu}$ precursor [30] and has also been reported for other metal oxide precursors [31]. Anyway, the feature we are interested in is the smooth mass gain observed in powders after decomposition. It corresponds to the oxidation of $\mathrm{Cu}_{2} \mathrm{O}$ or metallic $\mathrm{Cu}$ into $\mathrm{CuO}$ [32]. This process indicates that, despite the highly oxidative furnace conditions, copper becomes partially (or highly) reduced during decomposition. Recently, in situ XRD measurements during heating ramps have shown the successive states of oxidation that $\mathrm{Cu}$ acquires during decomposition on $\mathrm{Cu}$ acetate powders [33].

The degree of $\mathrm{Cu}$ reduction during decomposition of powders can be estimated by the mass-gain that is observed after decomposition, because $\mathrm{Cu}$ and $\mathrm{Cu}_{2} \mathrm{O}$ will become fully oxidized when the 
temperature is raised in an oxidative atmosphere. So, the mass gain measured from the end of decomposition up to $600^{\circ} \mathrm{C}$, (see the definition of in Fig. 8), is just a measure of the degree of reduction that copper has experienced during decomposition. From the TG curves of Fig. 8, it is clear that $\mathrm{Cu}$ reduction is lower for smaller $\mathrm{m}_{\mathrm{i}}$. This result is, as expected, according to the general argument that the out-diffusion of reducing species formed during decomposition [32] and the transport of oxygen into the sample is easier for smaller amounts of powder. In addition, combustion also contributes to this result. Since the decomposition rate is very high at the combustion front, the concentration of reducing volatile species there will be also very high and will partially displace oxygen, making the local atmosphere more reducing than in the absence of combustion. Since combustion (i.e. the abrupt step on the TG curves) accounts for almost the $100 \%$ of the mass-loss for the largest sample whereas it accounts roughly for $50 \%$ of the mass-loss for the smallest sample, we deduce that copper reduction during decomposition must be more pronounced as $\mathrm{m}_{\mathrm{i}}$ increases, as observed.

In the absence of combustion, thin films should experience minimum $\mathrm{Cu}$ reduction. Unfortunately, the $\mathrm{Cu}$ reduction feature characteristic of the TG curves of powders is absent from the curve of a thin film because decomposition still continues up to around $500{ }^{\circ} \mathrm{C}$ (Fig. 8) making it impossible to extract its degree of reduction. We can try to estimate it in thin films by extrapolating the results of powders to $m_{i}=0$. From the inset of Fig. 6 , it is clear that the degree of copper reduction will be very small in films. We have verified it by XRD measurements on powders and a film treated up to $300^{\circ} \mathrm{C}$ (Fig. 9). The diffraction curve obtained on $10 \mathrm{mg}$ of powders indicates that $\mathrm{CuO}$ is the residual phase whereas it is the only phase detected in the film (i.e. no $\mathrm{Cu}$ reduction is observed after decomposition of $\mathrm{Cu}$ acetate films in dry oxygen). 


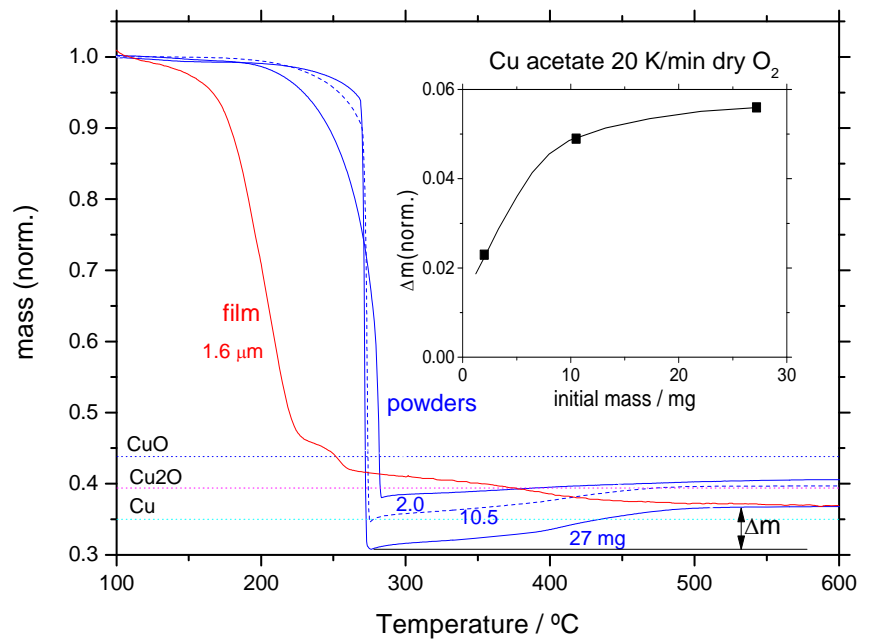

Figure 8.- Comparison between the TG decomposition curves of $\mathrm{Cu}$ acetate powders and one film in dry oxygen. The $\mathrm{y}$-axis of the inset corresponds to the mass increment due to complete oxidation of $\mathrm{Cu}$ and $\mathrm{Cu}_{2} \mathrm{O}$ (see arrow in the main figure) that follows acetate decomposition. The solid curve shows the general trend.

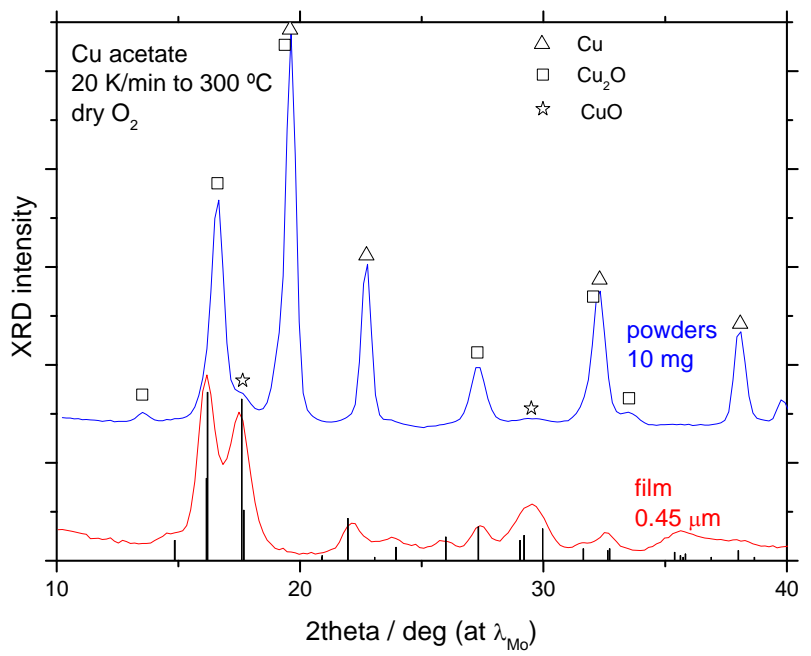

Figure 9.- XRD curves of $\mathrm{Cu}$ acetate treated up to $300^{\circ} \mathrm{C}$ in dry oxygen (vertical bars: expected peaks for $\mathrm{CuO}$ ). Whereas copper is highly reduced in the powder, it is fully oxidized in the film.

This example illustrates that, when used uncritically, the results on powders can lead to very erroneous conclusions for films (e.g. from any individual TG curve one would deduce a high reduction degree). However, when treated with caution, from the trend of the powders at the limit of zero initial mass we can deduce the approximate behaviour of films. 


\section{III.5.- Stability of intermediate products: metal fluorides and YBCO formation}

Although the usual aim of CSD is to obtain oxide films, sometimes decomposition of the precursor molecule leads to the formation of intermediate products such as metal carbonates or fluorides $[2,34$, 18]. In fact, at present, the most promising precursors for $\mathrm{YBCO}$ production are fluorine-based [16, 17]. With this choice, maximum critical currents are obtained. However, if we trusted on the thermal analysis of powders, we should conclude that this solution would be far from satisfactory because of the abundance of $\mathrm{BaF}_{2}$ in their decomposition product.

$\mathrm{Y}(\mathrm{TFA})_{3}$ powders decompose into fluorides and oxyfluorides that are stable up to $1000^{\circ} \mathrm{C}$ (Fig.10a) [35], a temperature much higher than that of YBCO film formation (around $800^{\circ} \mathrm{C}$ ). The product of $\mathrm{Ba}(\mathrm{TFA})_{2}$ decomposition $\left(\mathrm{BaF}_{2}\right)$ is still much more stable. One can see in Fig. $10 \mathrm{~b}$ that $\mathrm{BaF}_{2}$ begins to decompose above $1200^{\circ} \mathrm{C}$ [20]. Furthermore, we have treated a powder mixture obtained by precipitation from a solution containing the $\mathrm{Y}$ and $\mathrm{Ba}$ TFA precursors with molar ratio $\mathrm{Y}: \mathrm{Ba}=1: 2$, because studies on the mechanism of YBCO formation [17] indicate that $\mathrm{Y}$ and Ba fluorides are less stable when obtained from the mixture. The corresponding TG curve of Fig. $8 \mathrm{c}$ shows a mass loss step at $750^{\circ} \mathrm{C}$. The final mass at $810^{\circ} \mathrm{C}$ has a value consistent with a mixture of $\mathrm{BaF}_{2}, \mathrm{YOF}$ and $\mathrm{Y}_{2} \mathrm{O}_{3}$. In fact, $\mathrm{XRD}$ measurements reveal that the product contains two $\mathrm{Ba}$ oxyfluoride phases plus $\mathrm{BaF}_{2}$ and a complex fluoride of $\mathrm{Ba}$ and $\mathrm{Y}$ (Fig. 11), i.e., no oxides have been produced at the temperature that is used to obtain YBCO films. Consequently, thermal analysis of powders would lead to the erroneous prediction that $\mathrm{YBCO}$ preparation is not possible from TFA precursors.

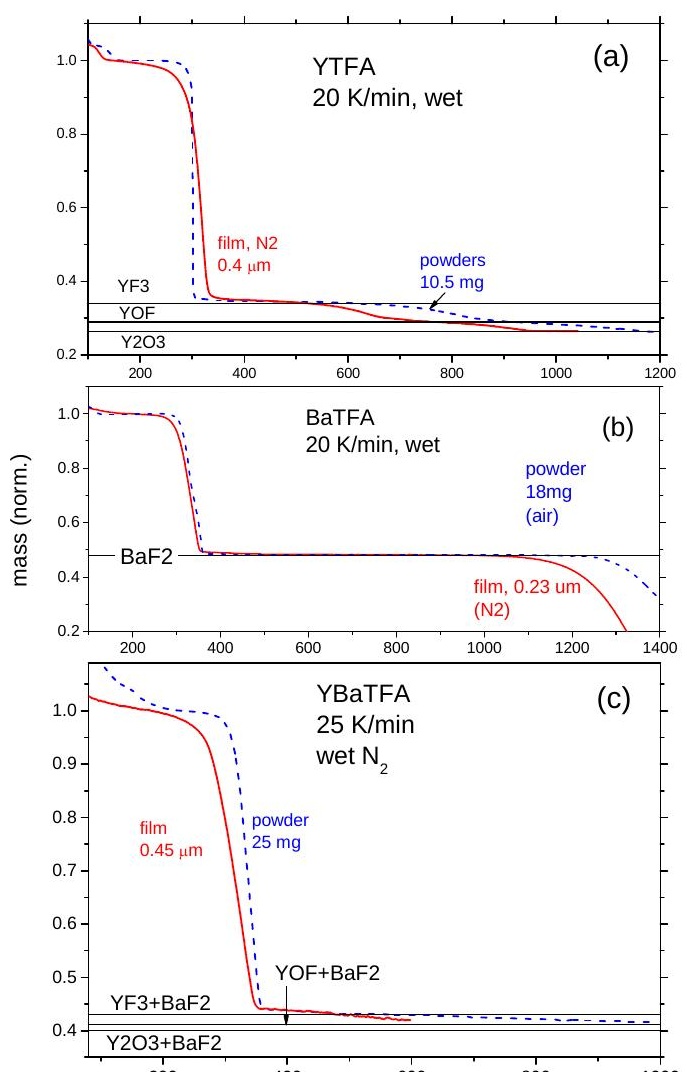


Figure 10.- TG curves of the decomposition of powders and films of $\mathrm{Y}(\mathrm{TFA})_{3}(\mathrm{a}), \mathrm{Ba}(\mathrm{TFA})_{2}$ (b) and a binary TFA precursor with molar ratio $\mathrm{Ba} Y \mathrm{Y}$ $=2: 1(\mathrm{c})$.

If we repeat these experiments with films, the result is quite different. Both $\mathrm{BaF}_{2}$ and $\mathrm{YF}_{3}$ films are less stable than powders; their decomposition temperature is lower by more than $100^{\circ} \mathrm{C}$ (Figs. 10a and $10 \mathrm{~b}$ ) $[21,15]$. The stability of $Y$ fluoride is still lower if films are obtained from the binary solution. Just after precursor decomposition, above $400^{\circ} \mathrm{C}$, their corresponding TG curve (Fig. 10c) already has a negative slope that continues up to the maximum temperature of this particular experiment $\left(600^{\circ} \mathrm{C}-\right.$ glass substrate) suggesting that $\mathrm{BaF}_{2}$ reaches complete decomposition. This point is nicely confirmed by the XRD curve measured on this film, where $\mathrm{Y}_{2} \mathrm{O}_{3}$ is the only phase containing $\mathrm{Y}$, all the $\mathrm{Y}$ fluorinated phases have disappeared and the main Ba-related phase is $\mathrm{BaF}_{2}$ (Fig. 11).

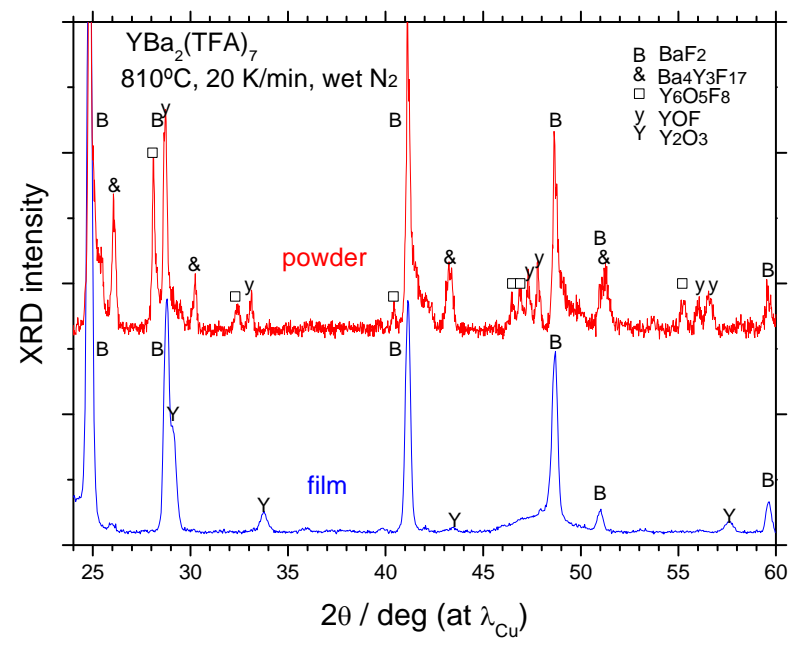

Figure 11.- $X R D$ of the products of decomposition of a binary $\mathrm{Y}(\mathrm{TFA})_{3} / 2 \mathrm{Ba}(\mathrm{TFA})_{2}$ precursor after heating them up to $810^{\circ} \mathrm{C}$ in wet $\mathrm{N}_{2}$.

The different behaviour of films can be explained by the fact that, thanks to the enhanced gas transport of volatiles or reactive gases, intermediate products tend to be less stable in films than in powders. In the particular case of metal fluorides, it has been shown that they decompose by reaction with water vapour and that the rate-limiting step is HF out-diffusion [35]. Therefore, its faster diffusion in films explains their lower decomposition temperature. 
Despite the improved behaviour of films and, in particular, of the binary film, $\mathrm{BaF}_{2}$ still survives at $800^{\circ} \mathrm{C}$, thus precluding $\mathrm{YBCO}$ formation. Since $\mathrm{YBCO}$ films are prepared at this temperature, we must conclude that $\mathrm{BaF}_{2}$ stability is lower when $\mathrm{Cu}(\mathrm{TFA})_{2}$ precursor enters into play. To reveal this effect, a ternary solution of $\mathrm{Y}, \mathrm{Ba}$ and $\mathrm{Cu}$ TFA precursors with molar ratio 1:2:3 has been prepared and, after precipitation, it has been heat treated in wet nitrogen. The complexity of this particular precursor mixture makes it very difficult to reach any conclusion about the nature of the products from the TG curves. So, we have analysed them by XRD.

One film of the ternary precursor with $0.9 \mu \mathrm{m}$ of nominal thickness was deposited on silicon substrates protected by a nanometric $\mathrm{Y}_{2} \mathrm{O}_{3}$ film and after treating it at $810^{\circ} \mathrm{C}$ during 30 min, its product has been compared with that of $9 \mathrm{mg}$ of powders treated at $920^{\circ} \mathrm{C}$. We have taken silicon instead of the substrates used for YBCO film production to avoid epitaxial crystallization, so that the observed differences between the film and powders can be unambiguously related to gas transport.

The XRD curve of powders (Fig.12a) shows that $\mathrm{BaF}_{2}$ is still the only Ba-containing crystalline phase like in the binary precursor; i.e., apparently, copper atoms have not diminished the stability of this phase. On the contrary, one can notice (Fig. 12b) an important diminution of the $\mathrm{BaF}_{2}$ content in the film. This result on the film is consistent with the interpretation that gas transport makes it easier YBCO synthesis in thin films than in powders even if epitaxial crystallization is prevented by using a silicon substrate.

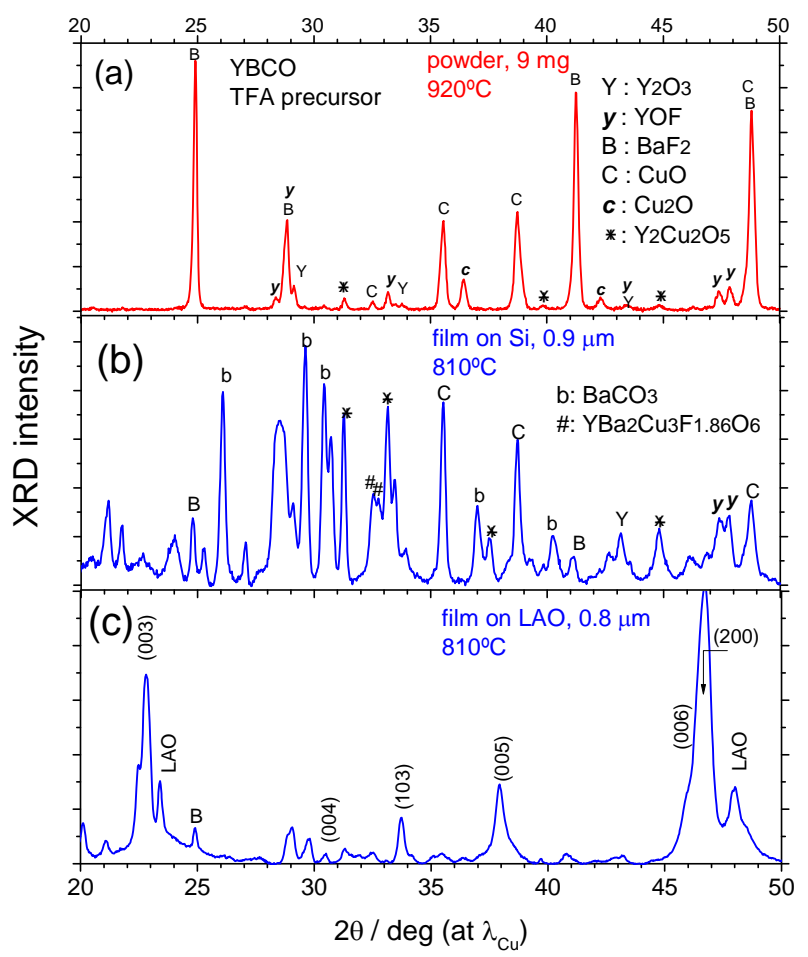

Figure 12.- $X R D$ of the decomposition products of a ternary 1:2:3 Y:Ba:Cu TFA precursor in the form of powders (a), in a film deposited on silicon (b) and on (001) $\mathrm{LaAlO}_{3}$ (LAO) single crystalline substrate (c). The indexed peaks in (c) refer to YBCO. 
Before leaving this section, we should remark that films on $\mathrm{LaAlO}_{3}$ substrates (where epitaxial crystallization occurs) treated at identical conditions are completely transformed into YBCO (Fig. 12c). This means that lattice match with the substrate does not only make possible epitaxy but it activates the reaction between the component oxides of YBCO.

\section{IV.- Conclusions}

The examples given above clearly show that films of metal organic precursors decompose differently than their corresponding powders: a) their decomposition temperature is lower; b) decomposition via combustion does not occur (so far, we have not found a single exception to these two conclusions); c) films are more sensitive to residual amounts of oxygen in the furnace atmosphere and d) the intermediate products obtained before oxide formation are less stable. These differences arise because, in thin films, gas exchange is easier, and the substrate offers an efficient path to heat dissipation and, eventually, promotes epitaxial growth. Our results raise the question about the usefulness of doing thermal analyses on powders for predicting the behaviour of films.

After decades of doing thermal analysis on powders by people that make films, any intention of discrediting this practice is nonsense. We want simply to remark that not only quantitative information may not be accurate enough (e.g. the decomposition temperature) but that even qualitative conclusions may be erroneous (e.g. combustion of films). In those cases where the decomposition evolves with the mass of powders, this evolution can serve to predict the behaviour of films. However, in the absence of such an evolution, the behaviour of films can only be deduced by general rules like those indicated in the previous paragraph.

We thus conclude that thermal analysis on films is very useful for the analysis of the preparation of oxide films and may be unavoidable in some instances. Although the sample mass must be lower than with powders, films of $1 \mathrm{mg}$ may already deliver significant results. This amount of sample can be analyzed without much difficulty by modern TG/DTA and DSC equipment.

\section{Acknowledgments}

We acknowledge the financial support from MICINN (MAT2011-28874-C02-01 and -02, Consolider Project NANOSELECT: CSD2007-00041), EU project EUROTAPES, (EUFP7 NMPLA2012280432) 
and by the Generalitat de Catalunya (Pla de Recerca 2009SGR-185, 2009-SGR-770 and XaRMAE). H.Eloussifi acknowledges financial support from the Tunisian Ministry of Higher Education and Scientific Research. The authors are indebted to Dr.Joan Pere López Olmedo and Dr.Xavier Fontrodona of STR, University of Girona, and Dr.Josep Bassas of CCT, University of Barcelona, for their technical assistance.

\section{References.-}

[1] F.F.Lange, Chemical Solution Routes to Single-Crystal Thin Films, Science 273 (1996) 903-909.

[2] R.Schwartz, T. Scheneller and R.Waser, Chemical Solution Deposition of Electronic Oxide Films, C. R. Chimie 7 (2004) 433-461.

[3] M.S.Bhuiyan, M.Paranthaman, and K.Salama, Solution-Derived Textured Oxide Thin Films - A Review, Supercond.Sci.Technol. 19 (2006) R1-R21.

[4] M. Gibert, T. Puig, X. Obradors, A. Benedetti, F. Sandiumenge, R. Huhne, Self-Organization of Heteroepitaxial $\mathrm{CeO}_{2}$ Nanodots Grown from Chemical Solutions, Adv. Mater. 19 (2007) 3937-3942.

[5] A.Cavallaro, F. Sandiumenge, J. Gazquez, T. Puig, X. Obradors, J. Arbiol, H.C. Freyhardt, Microstructure, and Surface Modification of Nanostructured $\mathrm{CeO}_{2}$ Films by Chemical Solution Deposition, Adv. Funct. Mater. 16 (2006) 1363-1372.

[6] M-G.Kim, M.G. Kanatzidis, A. Facchetti, T.J. Marks, Low-Temperature Fabrication of HighPerformance Metal Oxide Thin-Film Electronics Via Combustion Processing, Nature Materials 10 (2011) 382-388.

[7] U.Schoop, M.W. Rupich, C.Thieme, D.T. Verebelyi, W. Zhang, X. Li, T. Kodenkandath, N. Nguyen, E.Siegal, L.Civale, T. Holesinger, B. Maiorov, A.Goyal, Second Generation HTS Wire Based on Rabits Substrates and MOD YBCO, IEEE Trans. Appl. Supercond. 15 (2004) 2611-2616.

[8] M.W.Rupich, X.P. Li, C. Thieme, S. Sathyamurthy, S. Fleshler, D. Tucker, E. Thompson, J.

Schreiber, J. Lynch, D. Buczek, K. DeMoranville, J. Inch, P. Cedrone, J.Slack, Advances In Second Generation High Temperature Superconducting Wire Manufacturing And R\&D at American Superconductor Corporation, Supercond. Sci. Technol. 23 (2010) 014015.

[9] X. Obradors and T. Puig, Coated Conductors for Power Applications: Materials Challenges, Supercond. Sci. Technol. 27 (2014) 044003.

[10] T.Todorov, E. Cordoncillo, J.F. Sanchez-Royo, J. Carda, P. Escribano, CuInS 2 Films for Photovoltaic Applications Deposited by a Low-Cost Method, Chem.Mater. 18 (2006) 3145-3150. 
[11] P.Roura, J. Farjas, S.Ricart, M. Aklalouch, R. Guzman, J. Arbiol, T. Puig, A. Calleja, O. PeñaRodríguez, M. Garriga, X. Obradors, Synthesis of Nanocrystalline Ceria Thin Films by LowTemperature Thermal Decomposition of Ce-Propionate, Thin Solid Films 520 (2012) 1949-1953.

[12] N. Bassiri-Gharb, Y. Bastani, A. Bernal, Chemical Solution Growth of Ferroelectric Oxide Thin Films and Nanostructures, Chem. Soc. Rev. 43 (2014) 2125-2140.

[13] H.Eloussifi, J. Farjas, P. Roura, M. Dammak, Evolution of Yttrium Trifluoroacetate During Thermal Decomposition, J.Therm.Anal.Calorim. 108 (2012) 597-603.

[14] J.Farjas, A. Pinyol, Ch. Rath, P. Roura, E.Bertran, Study of the Oxide-Assisted Catalyst-Free Synthesis of Silicon Nitride Nanowires, Phys. Stat. Sol. A 203 (2006) 1307-1312.

[15] H.Eloussifi, J. Farjas, P. Roura, S. Ricart, T. Puig, X. Obradors, M. Dammak, Thermoanalytical Study of the Decomposition of Yttrium Trifluoroacetate Thin Films, Thin Solid Films 545 (2013) 200204.

[16] X.Obradors, T. Puig, A. Pomar, F. Sandiumenge, N. Mestres, M. Coll, A. Cavallaro, N. Roma, J. Gazquez, J.C. Gonzalez, O. Castano, J. Gutierrez, A. Palau, K. Zalamova, S. Morlens, A. Hassini, M. Gibert, S. Ricart, J.M. Moreto, S. Pinol, D. Isfort, J. Bock, Progress Towards All-Chemical Superconducting $\mathrm{YBa}_{2} \mathrm{Cu}_{3} \mathrm{O}_{7}$-Coated Conductors, Supercond. Sci. Technol. 2006, 19, S13-S26.

[17] X.Obradors, T. Puig, S. Ricart, M. Coll, J. Gazquez, A. Palau, X. Granados, Nanostructure and Vortex Pinning in Superconducting $\mathrm{YBa}_{2} \mathrm{Cu}_{3} \mathrm{O}_{7}$ Thin Films based on Trifluoroacetate Solutions, Supercond. Sci.Tecnol. 25 (2012) 12301.

[18] J.Farjas, D.Sanchez-Rodriguez, H.Eloussifi, R.Cruz Hidalgo, P.Roura, S.Ricart, T.Puig and X.Obradors, Can We trust on the thermal analysis of Metal Organic Powders for thin film preparation? in M.Jain, X.Obradors, Q.Jia and R.W.Schwartz (eds.), Solution synthesis of inorganic films and nanostructured materials, Mater.Res.Soc.Symp.Proc. vol. 1449, MRS, Warrendale, 2012, 13-18.

[19] P.Roura, J. Farjas, J. Camps, S. Ricart, J.Arbiol, T. Puig, X. Obradors, Decomposition Processes and Structural Transformations of Cerium Propionate into Nanocrystalline Ceria at Different Oxygen Partial Pressures, J. Nanopart. Res. 13 (2011) 4085-4096.

[20] J.Farjas, J. Camps, P. Roura, S. Ricart, T. Puig, X.Obradors, The Thermal Decomposition of Barium Trifluoroacetate, Thermochim.Acta 544 (2012) 77-83.

[21] H.Eloussifi, J. Farjas, P. Roura, S. Ricart, T. Puig, X. Obradors, M. Dammak, Thermal Decomposition of Barium Trifluoroacetate Thin Films, Thermochim.Acta 556 (2013) 58-62. 
[22] T.B.Lindemer, F.A. Washburn, C.S. MacDougall, R. Feenstra, O.B. Cavin, Decomposition of $\mathrm{YBa}_{2} \mathrm{Cu}_{3} \mathrm{O}_{7}-\mathrm{X}$ and $\mathrm{YBa}_{2} \mathrm{Cu}_{4} \mathrm{O}_{8}$ for $\mathrm{PO}_{2}<0.1 \mathrm{MPa}$, Physica C 178 (1991) 93-104.

[23] D.Sanchez-Rodriguez, H.Eloussifi, J.Farjas, P.Roura and M.Dammak, Thermal gradients in thermal analysis experiments: criterions to prevent inaccuracies when determining sample temperature and kinetic parameters, Thermochim.Acta 589 (2014) 37-46.

[24] W.Chen, F. Li, J. Yu, Combustion Synthesis and Characterization of Nanocrystalline CeO2-based Powders Via Ethylene Glycol-Nitrate Process, Mater.Lett. 60 (2006) 57-62.

[25] D.Sanchez-Rodriquez, J. Farjas, P. Roura, S. Ricart, N. Mestres, X. Obradors, T.Puig, Thermal Analysis for Low Temperature Synthesis of Oxide Thin Films from Chemical Solutions, J.Phys.Chem.C 117 (2013) 20133-20138.

[26] S.Jeong, J-Y. Lee, S.S. Lee, Y. Choi, B.H. Ryu, Impact of Metal Salt Precursor on LowTemperature Annealed Solution-Derived Ga-doped $\mathrm{In}_{2} \mathrm{O}_{3}$ Semiconductor for Thin-Film Transistors, J.Phys.Chem.C 115 (2011) 11773-11780.

[27] S.D.Bakrania, G.K. Rathore, S. Wooldridge, An Investigation of The Thermal Decomposition of Gold Acetate, J. Therm. Anal. Cal. 95 (2009) 117-122.

[28] J.C.De Jesus, I. Gonzalez, A. Quevedo, T. Puerta, Thermal Decomposition of Nickel Acetate Tetrahydrate: an Integrated Study by TGA, QMS and XPS Techniques, J. Molec. Catal. A: Chem. 228 (2005) 283-291.

[29] V.Logvinenko, O. Polunina, K. Mikhailov, B. Bokhonov, Study of Thermal Decomposition of Silver Acetate, J. Therm. Anal. Calorim. 90 (2007) 813-816.

[30] J.T.Dawley, P.G. Clem, T.J. Boyle, L.M. Ottley, D.L. Overmyer, M.P. Siegal, Rapid Processing Method for Solution Deposited $\mathrm{YBa}_{2} \mathrm{Cu}_{3} \mathrm{O}_{7-\delta}$ Thin Films, Physica C-Superconductivity and Its Applications 402 (2004) 43-151.

[31] T.Arii, A. Kishi, The Effect of Humidity on Thermal Process of Zinc Acetate, Thermochim.Acta. 400 (2003) 175-185.

[32] Z.Lin, D. Han, S. Li, Study on Thermal Decomposition of Copper(II) Acetate Monohydrate in Air, J. Therm. Anal. Calorim. 107 (2012) 471-475.

[33] S.A.Kondrat, T.E. Davies, Z. Zu, P. Boldrin, J.K. Bartley, A.F. Carley, S.H. Taylor, M.J. Rosseinsky, G.J. Hutchings, The Effect of Heat Treatment on Phase Formation of Copper Manganese Oxide: Influence on Catalytic Activity for Ambient Temperature Carbon Monoxide Oxidation, J. Catal. 281 (2011) 279-289. 
[34] A.Llordes, K. Zalamova, S.Ricart, A. Palau, A. Pomar, T. Puig, A. Hardy, M.K. van Bael, X. Obradors, Evolution of Metal-Trifluoroacetate Precursors in the Thermal Decomposition toward HighPerformance YBa2Cu3O7 Superconducting Films, Chem.Mater. 22 (2010) 1686-1964.

[35] H. Eloussifi, J. Farjas, P. Roura, J. Camps, M. Dammak, S. Ricart, T. Puig and X. Obradors, Evolution of Yttrium Trifluoroacetate during Thermal Decomposition, J.Therm. Anal. Calorim. 108 (2012) 589-596. 